\title{
Correction to: Patterns of School Victimization and Problem Behaviors: Longitudinal Associations with Socioeconomic Well-Being and Criminal Justice Involvement
}

\author{
Ryan D. Heath ${ }^{1}$ (D) $\cdot$ Kevin Tan ${ }^{2} \cdot$ Jennifer S. Guzzy ${ }^{1} \cdot$ Briyana Henry $^{3}$
}

Published online: 6 August 2021

(c) Springer Science+Business Media, LLC, part of Springer Nature 2021

\section{Correction to: Child \& Youth Care Forum https://doi.org/10.1007/s10566-021-09633-1}

While corrected versions have been added online and in the final publication, this correction is to alert readers of an early version of.
Heath, R. D., Tan, K., Guzzy, J. S., \& Henry, B. (2021). Patterns of school victimi- zation and problem behaviors: Longitudinal associations with socioeconomic well- being and criminal justice involvement. Child \& Youth Care Forum, 1-23. https://doi. org/10.1007/s10566-021-09633-1

that was published online on June 21,2021 , that " 2017 " should replace " 2016 " and " 16 " in several places where the article.

Tan, K., Heath, R. D., Das, A., \& Choi, Y. (2017). Gender differences in patterns of school victimization and problem behaviors during middle school and their relation to high school graduation. Youth \& Society, 51(3), 339-357. https://doi.org/10.1177/ 0044118 X17741143

is cited.

This article has also been added to the References section.

The original article has been updated.

Publisher's Note Springer Nature remains neutral with regard to jurisdictional claims in published maps and institutional affiliations.

The original article can be found online at https://doi.org/10.1007/s10566-021-09633-1.

Ryan D. Heath

rdheath@syr.edu

1 School of Social Work, Syracuse University, 244 White Hall, Syracuse, NY 13244, USA

2 School of Social Work, University of Illinois Urbana-Champaign, Champaign, IL, USA

3 Silver School of Social Work, New York University, New York, NY, USA 